\title{
Automation Models Turn On and Turn Off Electric Switches In Accordance With The Time Specified Using Arduino
}

\author{
${ }^{1}$ April Firman Daru, ${ }^{2}$ Heddy Tyas Darmawan \\ Jurusan Teknik Informatika USM Universitas Semarang \\ i.rman@usm.ac.id, ${ }^{2}$ heddytyas306@gmail.com
}

\begin{abstract}
Abstrak
Pemakain lampu yang terus menerus karena lupa untuk mematikan mengakibatkan biaya listrik menjadi lebih mahal. Berkaitan dengan hal tersebut, akan dilakukan suatu penelitian tentang alat sistem saklar yang menggunakan pengatur waktu untuk menghidupkan dan mematikannya arus listriknya secara otomatis. Saklar ini dapat menghidupkan dan mematikan lampu secara otomatis dengan waktu yang sudah ditentukan yang dikendalikan oleh mikrokontroller Atmega328 (Arduino UNO R3 DIP). Relay Module yang digunakan sebagai pemicu untuk menghidupkan dan mematikan saklar dan juga DS3231 RTC Module sebagai pengatur waktu dalam detik, menit, dan jam. Tujuan dari pembuatan alat ini adalah diharapkan dapat mengontrol waktu nyala lampu, sehingga pemakain lampu dapat diatur.
\end{abstract}

Kata kunci-Saklar Waktu Otomatis, Arduino Uno, Mikrokontroler, Modul Relay, Modul DS3231 RTC

\section{Abstract}

Continuous usage of the lamp because it forgot to turn off resulted in electricity costs becoming more expensive. In this regard, a research will be conducted on a switch system that uses a timer to automatically turn on and turn off the electric current. This switch can turn on and turn off the lights automatically with a predetermined time which is controlled by the Atmega328 microcontroller (Arduino UNO R3 DIP). The Relay Module is used as a trigger to turn on and off the switch and also the DS3231 RTC Module as a timer in seconds, minutes and hours. The purpose of making this tool is expected to be able to control the time of the lights, so that the use of lights can be arranged.

Keywords-Automatic Time Switch, Arduino Uno, Microcontroller, Relay Module, DS3231 RTC Module

\section{Pendahuluan}

Dalam keidupan sehari - hari energi listrik merupakan sumber eneri utama yang banyak dimanfaatkan dan dibutuhkan oleh manusia. Energi listrik merupakan salah satu faktor pendukung penting bagi kehidupan manusia karena banyak sekali peralatan yang biasa menggunakan listrik sebagai sumber energinya. Dengan pentingnya energi listrik bagi kehidupan sehari-hari, maka pemanfaatan energi listrik sangat penting untuk dijaga, karena jumlah energi listrik yang terbatas.

Seiring berajalannya waktu, manusia mengabaikan pentingnya hal dalam penggunaan energi listrik yang mengakibatkan pemborosan energi listrik. Karena kurangnya kesadaran dan perilaku manusia dalam menggunakan energi listrik yang menyebabkan kebiasaan pemborosan energi listrik yang mengakibatkan mahalnya biaya listrik. Sebagai contoh, penggunaan lampu yang berlebihan saat kita meninggalkan rumah dalam kurun waktu yang cukup lama mengakibatkan pemborosan listrik, hal ini akan menyebabkan pemanasan global yang akan berakibat fatal bagi manusia.

Untuk mengatasi kebiasaan pemborosan energi listrik, maka diperlukan teknologi yang dapat mengurangi beban biaya listrik dengan cara mengontrol penggunaan energi listrik, pada 
Pengembangan Rekayas a dan Teknologi, Vol 15, No. 2, Desember 2019, pp 107-111

p-ISSN: 1410-9840 \& e-ISSN: 2580-8850

http $/ /$ journals.usm.ac.id/index.php/jprt/index

penelitian yang dilakukan oleh Heru Supriyono, Bruri Setio Wahyudi, dan Bana Handaga (2013) yang berjudul "Saklar Lampu Otomatis dan Timer yang Dapat Diatur Untuk Menyalakan dan Memadamkan Sound Sistem Pada Persewaan Studio Musik"[1], dan penelitian yang dilakukan oleh Trisiani Dewi Hendrawati dan Indra Lesmana (2016) yang berjudul "Rancang Bangun Saklar Lampu Otomatis dan Monitoring Suhu Rumah Menggunakan VB.Net dan Arduino"[2], serta penelitian Bakhtiar dan Suherman (2015) yang berjudul "Realisasi Sistem Switch Lampu Penerangan Ruangan Otomatis Untuk Meningkatkan Efisiensi Energi Listrik"[3] adanya upaya dalam penghematan energi listrik, tetapi memiliki kekurangan yaitu masih dilakukan secara manual dan tidak menggunakan sistem otomatis, dengan ini penulis mendapat ide, yaitu dengan menciptakan alat pemutus saklar otomatis dengan waktu yang sudah diatur. Saklar waktu otomatis ini dirancang untuk menghidupkan dan mematikan saklar listrik pada lampu, pendingin ruangan, dan peralatan elektronik lainnya. Rancang bangun pada saklar waktu otomatis ini menggunakan Relay Module sebagai pemicu untuk mematikan dan menghidupkan saklar dengan waktu yang sudah ditentukan pada DS3231 RTC Module. Saklar waktu otomatis ini akan diatur untuk mematikan dan menghidupkan sebuah lampu setiap menitnya.

Berdasarkan uraian tersebut maka diperlukan sebuah rancang bangun otomatis untuk menghidupkan serta mematikan saklar listrik pada lampu setiap menitnya. Sehingga energi listrik dapat digunakan secara efisien agar dapat mengurangi beban biaya listrik.

\section{Metode Penelitian}

Metode penelitina merupakan suatu prosedur yang digunakan dalam pengumpulan, pengolahan dan penganalisaan data dengan cara - cara ilmiah. Adapun tahapan metodologi peneleitian adalah sebagai berikut:

\section{Pengumpulan Data}

Data adalah sumber atau bahan mentah yang sangat berharga bagi suatu proses yang menghasilkan informasi. Oleh karena itu, pengumpulan data perlu dilakukan secara cermat sehingga data - data yang diperoleh dapat bermanfaat dan berkualitas. Adapun metode pengumpulan data yang penulis gunakan adalah Studi Pustaka, yaitu metode pengumpulan data yang dilakukan dengan mencari, membaca dan mengumpulkan dokumen-dokumen seperti buku, artikel dan literatur mengenai bagaimana cara menghemat dalam penggunaan energi listrik sebagai referensi, dan literaturliteratur lainnya yang berhubungan dengan topik penelitian yang akan dilakukan.

\section{Pengembangan Sistem}

Dalam perancangan sistem diperlukan cara-cara untuk mengembangkan sistem tersebut guna mendapatkan sistem yang handal dan sesuai dengan yang diharapkan. Metode pengembangan sistem yang digunakan dalam Penelitian ini adalah metode Prototype.

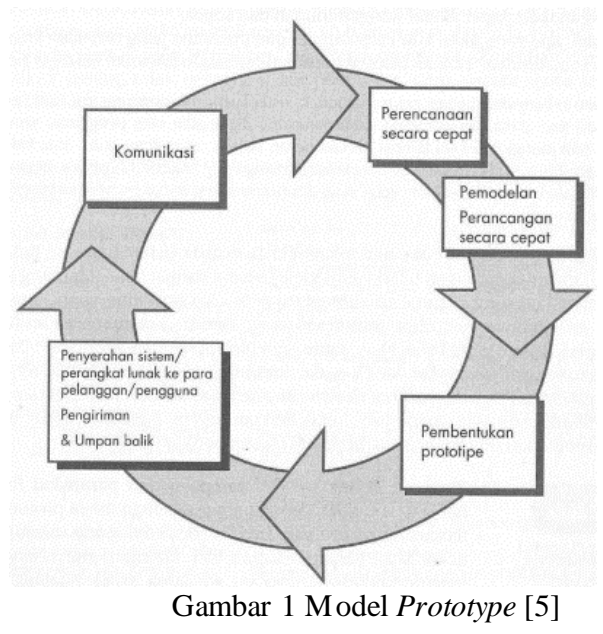

\section{Hasil dan Pembahasan}

\section{Flowchart Design System}

Flowchart System pada penelitan ini adalah sebagai berikut : 
Pengembangan Rekayas a dan Teknologi, Vol 15, No. 2, Desember 2019, pp 107-111

p-ISSN: 1410-9840 \& e-ISSN: 2580-8850

http $/ /$ journals.usm.ac.id/index.php/jprt/index

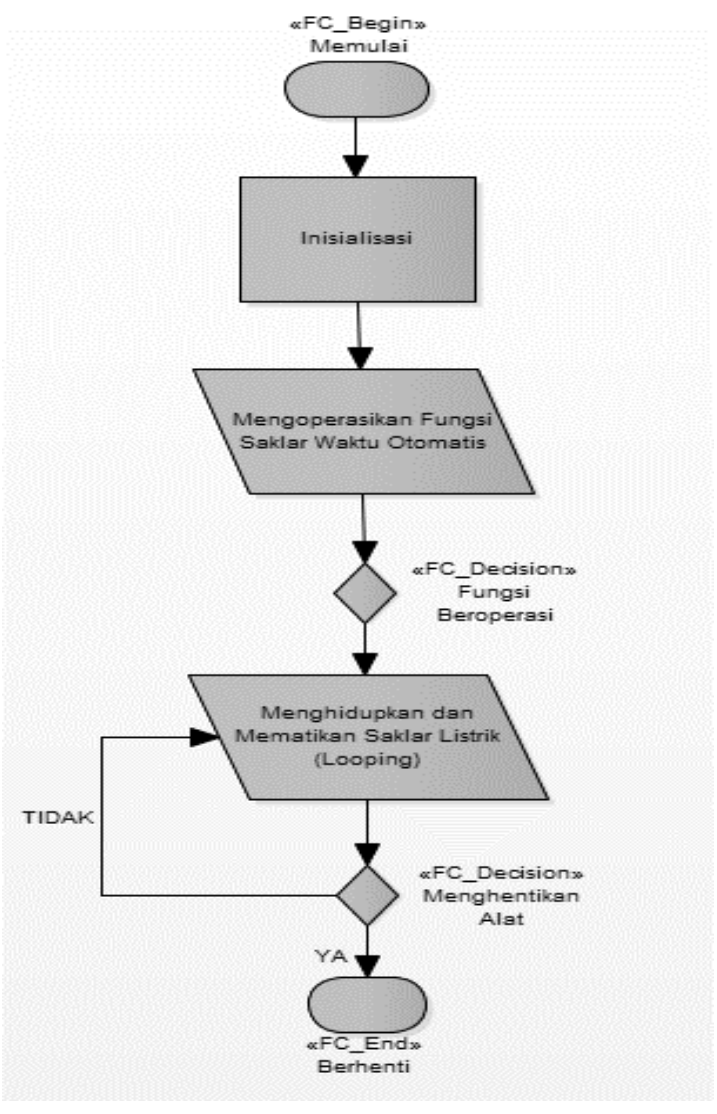

Gambar 2. Flowchart Saklar Waktu Otomatis

\section{Diagram B lok}

Diagram blok merupakan salah satu bagian terpenting dalam perancangan, karena dari diagram blok dapat diketahui prinsip kerja keseluruhan rangkaian.

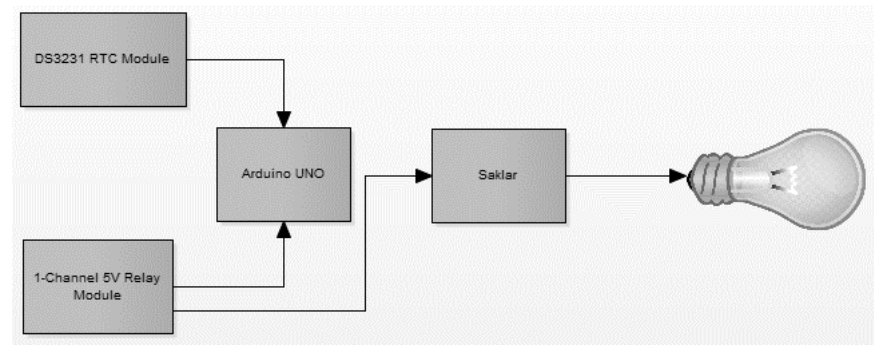

Gambar 3. Diagram Blok Model Perancangan

\section{Skematik Keseluruhan Rangkaian}

Dalam skematik rangkaian ini menerangkan keseluruhan prototype yang penulis rancang. terdapat breadboard, board arduino, DS3231 rtc module, dan 1-Channel 5V relay module yang saling terhubung. Arduino Uno sebagai kontroler dari keseluruhan rangkaian yang bertugas menerima dan mengolah data. Sedangkan 1-Channel $5 \mathrm{~V}$ relay module sendiri digunakan sebagai alat pemicu untuk menghidupkan dan mematikan saklar listrik. Adapun skematik rangkaian yang telah penulis rancang adalah sebagai berikut :

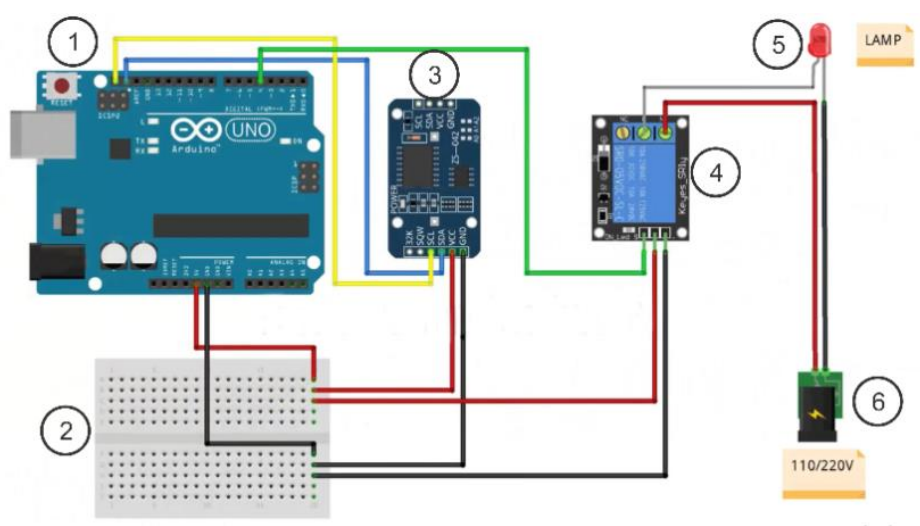

Gambar 7. Skema Rangkaian Saklar Waktu Otomatis Keterangan :

1. Arduino Uno

2. Bread Board

3. DS3231 RTC (Real Time Clock) Module

4. 1-Channel 5V Relay Module

5. Lampu

6. Penghubung Daya Listrik / $A C$ Power

Keterangan warna kabel jumper :
1. Kuning : Kabel SCL
2. Biru : Kabel SDA
3. Hijau : Kabel Daya Relay
4. Merah : Kabel VCC
5. Hitam : Kabel GND

Berikut adalah hasil keseluruhan rangkaian dari saklar waktu otomatis yang sudah dibuat berdasarkan blok model perancangan dan skematik keseluruhan rangkaian saklar waktu otomatis. 
Pengembangan Rekayas a dan Teknologi, Vol 15, No. 2, Desember 2019, pp 107-111

p-ISSN: 1410-9840 \& e-ISSN: 2580-8850

http//journals.usm.ac.id/index.php/jprt/index

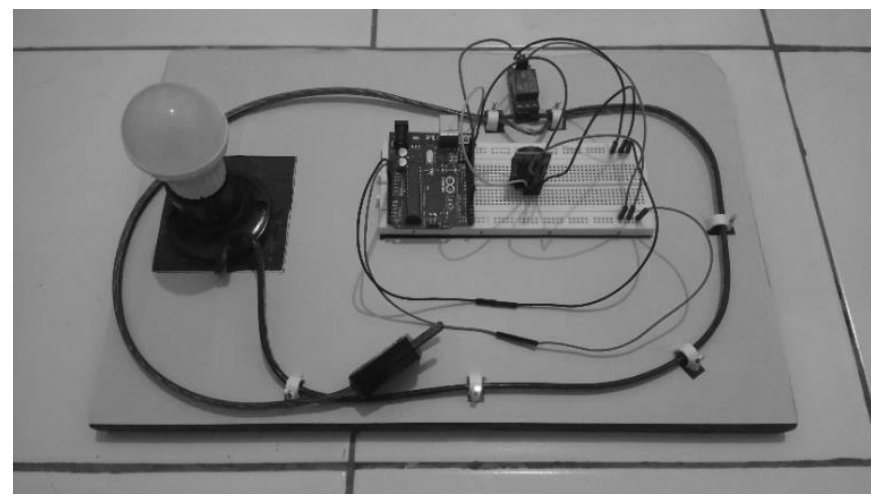

Gambar 8. Hasil Keseluruhan Rangkaian Saklar Waktu Otomatis

\section{Pengujian Sistem}

Pengujian sistem adalah serangkaian pengujian yang berbeda-beda yang bertujuan untuk mengetahui sistem yang kita bangun sudah baik atau belum. Pengujian yang akan di gunakan dalam pengujian sistem ini yaitu pengujian alpha dan pengujian beta.

\section{Pengujian}

Pengujian dilakukan untuk mengetahui apakah sistem bekerja dengan normal, seperti menguji tiap modul - modul pada sistem, serta menguji respon perangkat keras.

Tabel 1. Hasil Pengujian

\begin{tabular}{|c|c|c|c|}
\hline $\begin{array}{c}\text { Input / } \\
\text { Pengujian }\end{array}$ & Fungsi & Output & Hasil Uji \\
\hline Inisialisasi & $\begin{array}{l}\text { Menyalakan perangkat } \\
\text { keras }\end{array}$ & $\begin{array}{l}\text { Perangkat menyala dengan } \\
\text { ditandai indikator yang menyala }\end{array}$ & Berhasil \\
\hline $\begin{array}{l}\text { Hubungkan ke } \\
\text { AC Power }\end{array}$ & $\begin{array}{l}\text { Menghubungkan kabel } \\
\text { pada lampu dan Relay ke } \\
\text { AC Power dengan arus } \\
\text { sebesar } 220 \mathrm{~V}\end{array}$ & $\begin{array}{l}\text { Lampu dalam keadaan mati, } \\
\text { menunggu Relay sebagai saklar } \\
\text { untuk menghubungkan arus } \\
\text { listrik agar lampu dapat hidup }\end{array}$ & Berhasil \\
\hline $\begin{array}{l}\text { Running } \\
\text { Program }\end{array}$ & $\begin{array}{l}R T C \text { akan berjalan sesuai } \\
\text { waktu nyata dan setiap } 12 \\
\text { jam Relay akan otomatis } \\
\text { memutuskan dan } \\
\text { menyambungkan arus } \\
\text { listrik dari AC Power ke } \\
\text { lampu }\end{array}$ & 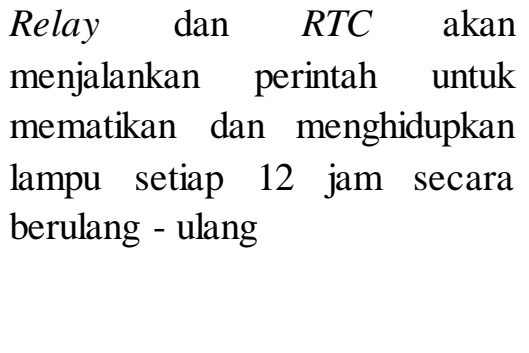 & Berhasil \\
\hline
\end{tabular}

\section{KESIMPULAN}

Sistem yang telah dibangun dapat berfungsi sebagai pengendali saklar otomatis yang dapat menghidupkan dan mematikan lampu sesuai waktu yang telah ditentukan, hal ini dibuktikan dengan pengujian sistem dan dilihat dari responsi pada pengguna yang berpotensi untuk menggunakan sistem Saklar Waktu Otomatis ini. Kedepan dapat dilakukan peningkatan performa sistem dengan melakukan Perbaikan source code untuk meningkatkan kualitas akurasi pada pewaktu digital (Real Time Clock) Saklar Waktu Otomatis yang sebelumnya berada pada detik 12 ,
27, 42, dan 57 menjadi akurat dan tepat pada detik 0, 15, 30, dan 45. Perlu ditambahkan LCD guna memberikan notifikasi teks kepada pengguna. Penambahan fitur tombol untuk memudahkan mengatur waktu hidup dan mati saklar listrik tanpa perlu memprogram ulang arduino pada Saklar Waktu Otomatis ini. 
Pengembangan Rekayas a dan Teknologi, Vol 15, No. 2, Desember 2019, pp 107-111 p-ISSN: $1410-9840$ \& e-ISSN: 2580-8850

http $/ /$ journals.usm.ac.id/index.php/jprt/index

\section{DAFTAR PUSTAKA}

[1] Supriyono, Heru, Wahyudi, Bruri Setio, dan Handaga Bana, 2013, Saklar Lampu Otomatis dan Timer yang Dapat Diatur Untuk Menyalakan dan Memadamkan Sound Sistem Pada Persewaan Studio Musik, Univ. Muhammadiyah Surakarta, Surakarta.
[2] Hendrawati, Dewi, dan Lesmana, Indra, 2016, Rancang Bangun Saklar Lampu Otomatis dan Monitoring Suhu Rumah Menggunakan VB.Net dan Arduino, Politeknik Sukabumi, Sukabumi.

[3] Bakhtiar dan Suherman, 2015, Realisasi Sistem Switch Lampu Penerangan Ruangan Otomatis Untuk Meningkatkan Efisiensi Energi Listrik, Jurnal Arus Elektro Indonesia, Jember. 